$\operatorname{cocos}(2004), 16,65-73$

Printed in Sri Lanka

\title{
SOIL PHOSPHORUS TEST METHODS CALIBRATION BY FIELD EXPERIMENTAL DATA FOR THE SOILS OF LOW COUNTRY INTERMEDIATE ZONE OF SRI LANKA
}

\author{
D M D I Wijebandara
}

Coconut Research Institute, Lunuwila, Sri Lanka

\begin{abstract}
Green house studies showed that the $2.5 \%$ Acetic acid (HAC), Olsen's bicarbonate ( $0.5 \mathrm{M} \mathrm{NaHCO}_{3}$ ), Anion Exchange Resin (AER) and Anion Exchange Resin + Cation Exchange Resin (AER + CER) methods were satisfactory for the estimation of plant available phosphorus $(P)$ of soils of the Low Country Intermediate Zone of Sri Lanka. The objective of this study was to calibrate the four extraction methods by field experiments. Relative yield of Pueraria phaseoloides grown in field on five soil series treated with and without $\mathbf{P}$ fertilizer, but with basal treatment of nitrogen, potassium and magnesium fertilizer were employed as the plant index for soil $P$ status. Soil $P$ status of each soil prior to treatment was determined by the four extraction methods.

The $2.5 \% \mathrm{HAC}$ - P values showed the best correlation with relative dry matter yield of Pueraria by fitting significantly to the Cate and Nelson model with $R^{2}$ of $0.628(P<0.01)$. Both AER $-P$ and $A E R+C E R-P$ values showed the poor correlation with $R^{2}$ of $0.460(P<0.05)$ compared to HAC P. $\mathrm{NaHCO}_{3}-\mathrm{P}$ showed poorest correlation with $\mathrm{R}^{2}$ of $0.449(\mathrm{P}<0.05)$. The $2.5 \%$ HAC - P was found to be superior to others as it accounted for 62.8 $\%$ of the variation of relative yield against $45-46 \%$ by the other extractants. Threshold $P$ levels as determined by the correlation data were $7.8,3.84,5.34$ and $8.47 \mathrm{mg} / \mathrm{kg}$ for $2.5 \%$ HAC - P, AER - P, (AER + CER) $\mathrm{P}$ and $\mathrm{NaHCO}_{3}-\mathrm{P}$ respectively. The $2.5 \% \mathrm{HAC}$ method was found to be the most suitable $P$ extraction method for Low Country Intermediate Zone of Sri Lanka.
\end{abstract}

\section{INTRODUCTION}

Soil phosphorus (P) estimation by laboratory methods is of major importance in an effective phosphate fertilizer recommendation programme. A large number of soil $P$ tests for plant available soil $P$ estimation are found in literature. But none of the methods can be recommended for any soil, unless such methods are evaluated and properly calibrated with respect to a particular soil - plant combinations. 
Evaluation of methods for the determination of available $P$ of some coconut growing soils in Low Country Intermediate Zone of Sri Lanka by green house pot experiments revealed that $2.5 \%$ Acetic acid (HAc) (Anon, 1985), Olsen's Bicarbonate (0.5 M NaHCO 3 ) (Olsen et al., 1954), Anion Exchange Resin (AER) and Anion Exchange Resin + Cation Exchange Resin (AER + CER) (Somasiri and Edwards, 1992) extraction were suitable (Wijebandara and Somasiri, 1994). But the $P$ values by the above methods cannot be interpreted meaningfully unless each of them are calibrated by field experiment. The objective of the present study was to calibrate the $2.5 \%$ HAC method, $0.5 \mathrm{M} \mathrm{NaHCO}_{3}$ method, AER method and AER + CER methods by field experiments with respect to Pueraria phaseoloides which is an important cover crop grown under coconut.

\section{MATERIALS AND METHODS}

A field experiment was design to study the plant response to the applied $P$ in ten coconut growing soils. Field experiment was conducted in top (A horizon) and sub (B horizon) soils of five different soil series located in Bandirippuwa estate of the Coconut Research Institute, Lunuwila (Intermediate Zone, Low country). The soils were Boralu series, Pallama series, Madampe series, Sudu series and Lunuwila series. The brief description of soil series, chemical and the physical characteristics of each soil is given in Table 1. 
Table 1: Description of each soil series, Chemical and physical characteristics of soils used for the field experiment

\begin{tabular}{|c|c|c|c|c|c|c|c|c|c|}
\hline Great soil group & Soil series & Description & $\begin{array}{c}\text { pH 1:5 } \\
\text { soil: } \mathrm{H}_{2} \mathrm{O}\end{array}$ & $\begin{array}{c}E C \\
\mu \mathrm{mho} / \mathrm{cm}\end{array}$ & $\begin{array}{c}\text { Sand } \\
\%\end{array}$ & $\begin{array}{l}\text { Silt } \\
\%\end{array}$ & $\begin{array}{c}\text { Clay } \\
\%\end{array}$ & $\overline{\text { Total N }}$ & $\begin{array}{c}\text { Organic } \\
\text { Matter } \\
\%\end{array}$ \\
\hline Red Yellow Podzolic (RYP) & Boralu (BOR) & Top soil (A) & 4.86 & 41.68 & 77.87 & 17.05 & $\mathbf{3 . 4 5}$ & 890 & 1.76 \\
\hline Red Yellow Podzolic (RYP) & Boralu (BOR) & Sub soil (B) & 4.54 & 25.07 & 78.20 & 10.98 & 4.58 & 525 & 1.12 \\
\hline Red Yellow Podzolic (RYP) & Pallama (PAL) & Top soil (A) & 5.19 & 37.15 & 85.54 & 7.08 & 3.40 & 470 & 0.97 \\
\hline Red Yellow Podzolic (RYP) & Pallama (PAL) & Sub soil (B) & 4.83 & 34.13 & 87.14 & 8.50 & 3.28 & 336 & 0.63 \\
\hline Latosols and regosols on old red and yellow sands & Madampe(MDP) & Top soil (A) & 5.32 & 32.62 & 94.51 & 2.78 & 3.10 & 265 & 0.47 \\
\hline Latosols and regosols on old red and yellow sands & Madampe(MDP) & Sub soil (B) & 5.23 & 25.07 & 88.42 & 3.30 & 3.90 & 220 & 0.33 \\
\hline Latosols and regosols on old red and yellow sands & Sudu (SUD) & Top soil (A) & 5.09 & 28.09 & 97.73 & 1.58 & 3.45 & 377 & 0.90 \\
\hline Latosols and regosols on old red and yellow sands & Sudu (SUD) & Sub soil (B) & 5.01 & 26.58 & $\mathbf{9 3 . 5 7}$ & 2.53 & 3.03 & 345 & 0.68 \\
\hline Alluvial soils & Lunuwila (LUN) & Top soil (A) & 5.32 & 29.60 & 94.62 & 0.90 & 2.68 & 291 & 0.53 \\
\hline Alluvial soils & Lunuwila (LUN) & Sub soil (B) & 5.27 & 22.05 & 97.60 & 1.55 & 2.80 & 235 & 0.36 \\
\hline
\end{tabular}

A-A horizon (Top soil), B - B horizon (Sub soil) 
The beds of dimensions $1.5 \mathrm{~m} \times 1.5 \mathrm{~m}$ were prepared in Boralu series, Pallama series, Madampe series, Sudu series and Lunuwila series soils. In each soil, beds were prepared including two depths; viz., the top soil ranging from $0-20 \mathrm{~cm}$ from the surface (A horizon) and the sub soil obtained after completely removing the top soil. The surface gap occurred due to removal of top soils were filled with the sub soil taken from the surrounding areas. The beds were arranged in the randomized block design with three replicates in each of which there were two treatment plots, $+P$ and $-P$. For each depth, beds were prepared separately.

Two phosphorus treatments were applied viz., no $P$ application $(-P), P$ application (+P) at the rate of $595.24 \mathrm{~kg}$ of $\mathrm{Ca}\left(\mathrm{H}_{2} \mathrm{PO}_{4}\right)_{2}$ (TSP) per ha. Basal dose was applied at the rate of $95.24 \mathrm{~kg}$ of $\left(\mathrm{NH}_{4}\right)_{2} \mathrm{SO}_{4}$ per ha. as $\mathrm{N}, 119.05$ $\mathrm{kg}$ of $\mathrm{KCl}$ per ha. as $\mathrm{K}$ and $59.52 \mathrm{~kg}$ of $\mathrm{MgSO}_{4} .7 \mathrm{H}_{2} \mathrm{O}$ per ha. as $\mathrm{Mg}$.

Pre-germinated Pueraria phaseoloides seedlings were planted at distances of $30 \mathrm{~cm}$ between rows and $15 \mathrm{~cm}$ between plants in each bed. Three months after planting, vegetative part of Pueraria were harvested within an area of $0.5 \mathrm{~m}^{2}$ and fresh and dry weights of harvested materials were recorded. Percent Relative yield (RY\%) of the crop in each soil was calculated as,

$$
\text { RY } \%=\frac{\text { Yield at }-\mathrm{P} \text { treatment }}{\text { Yield at }+\mathrm{P} \text { treatment }} \times(100)
$$

The dry weight of vegetative parts was taken as the yield of the Pueraria. Total Phosphorus content of vegetative parts of Pueraria was estimated by wet digestion with $\mathrm{HNO}_{3}: \mathrm{HClO}_{4}$ mixed at $1: 4$ ratio (Manual of analytical methods, 2000)

Soils were sampled prior to treatment application up to a depth of $30 \mathrm{~cm}$ from each replicate and bulked. Air dried $2 \mathrm{~mm}$ sieved soils were analyzed for available $P$ by $2.5 \% \mathrm{HAc}$ method, $0.5 \mathrm{M} \mathrm{NaHCO}_{3}$, AER method and AEP + CER method. Phosphorus in solution resulting in each extraction was estimated by the molybdenum- blue method (Murphy and Riley, 1962).

2.5\% Acetic acid extraction: (Anon, 1985)

A sample of $2.5 \mathrm{~g}$ soil was shaken with $100 \mathrm{ml}$ of $2.5 \%(\mathrm{v} / \mathrm{v})$ acetic acid solution for $2 \mathrm{~h}$. The mixture was filtered through Whatman no 42 filter paper and the filtrate was analyzed for $P$. 
Olsen's Bicarbonate extraction: (Olsen et. al., 1954)

Five grams of soil was shaken with $100 \mathrm{ml}$ of $0.5 \mathrm{~m}$ sodium bicarbonate solution ( $\mathrm{pH} 8.5$ ) (with $5 \mathrm{ml}$ of $0.5 \%$ polyacrylamide in one liter of $\mathrm{NaHCO}_{3}$ ) for 30 minutes. The mixture was filtered through Whatman 42 filter paper and the $\mathrm{pH}$ of the filtrate was adjusted to 5 using paranitrophenol indicator, and the filtrate was analyzed for $P$.

Anion Exchange Resin extraction: (Sibbesen, 1977 and 1978)

Five grams of soil was weighed into a $250 \mathrm{ml}$ polypropylene bottle, and 100 $\mathrm{ml}$ distilled water and $4 \mathrm{ml}$ of anion exchange resin (IRA $400 \mathrm{Cl}^{-}$) in a mesh bag was added to each bottle. The contents were shaken in an end-overend shaker for $4 \mathrm{~h}$. The resin bags were recovered, washed with distilled water to make them free of soil residues and absorbed phosphate onto resin was eluted by shaking each resin bag in $50 \mathrm{ml}$ of $1 \mathrm{M} \mathrm{NH}_{4} \mathrm{Cl}$ solution for 30 minutes, The elute was analyzed for $P$.

\section{Anion Exchange Resin + Caion Exchange Resin (AER + CER) extraction: (Somasiri and Edwards, 1992)}

Five grams of soil was weighed into a $250 \mathrm{ml}$ polypropylene bottle, and 100 $\mathrm{ml}$ distilled water, $3 \mathrm{ml}$ of cation exchange resin (Duolite $255, \mathrm{NH}^{+}$) and 4 $\mathrm{ml}$ of anion Exchange resin (IRA 400, $\mathrm{Cl}^{-}$) filled into separate mesh bags were added to each bottle. The contents were shaken in an end -over-end shaker for $4 \mathrm{~h}$. The resin bags were recovered and washed with distilled water to make them free of soil residues. Phosphate sorbed onto resins were eluted by shaking each pair of resin bags in $50 \mathrm{ml} 1 \mathrm{M} \mathrm{NH} 4 \mathrm{Cl}$ solution for 30 minutes, and the elute was analyzed for $P$.

Analytical data were analyzed according to Cate and Nelson statistical procedure (Cate and Nelson, 1971) and threshold levels for soil P were determined.

\section{RESULTS AND DISCUSSION}

According to $\mathrm{pH}$ measurement in 1:5 soil- water suspension (Table 1) seven soils (including $A$ and $B$ horizon) prior to $P$ treatment showed strongly acidic reaction ( $\mathrm{pH} 5.0-5.5$ ) and three soils showed very strongly acidic reaction ( $\mathrm{pH} 4.5-5.0$ ) (Troug, 1948). Laboratory estimates of $P$ in different soils obtained by individual methods were quite variable (Table 2). 
Table 2 : Extractable phosphorus content of soils used for the field experiment as estimated by different methods

\begin{tabular}{lcccc}
\hline Soil series & \multicolumn{4}{c}{ Soil P test method } \\
\cline { 2 - 5 } & $\begin{array}{c}2.5 \% \text { HAc } \\
\mathrm{mg} / \mathrm{kg}\end{array}$ & $\begin{array}{c}\text { Olsen 's } \\
\mathrm{mg} / \mathrm{kg}\end{array}$ & $\begin{array}{c}\text { AER }-4 \mathrm{~h} \\
\mathrm{mg} / \mathrm{kg}\end{array}$ & $\begin{array}{c}\text { AER + CER - } \\
4 \mathrm{~h} \\
\mathrm{mg} / \mathrm{kg}\end{array}$ \\
\hline BOR - A & 101.05 & 22.45 & 7.00 & 21.31 \\
BOR - B & 5.75 & 8.23 & 3.39 & 5.34 \\
PAL - A & 82.41 & 4.19 & 5.43 & 17.08 \\
PAL - B & 13.25 & 9.76 & 3.84 & 4.73 \\
MDP - A & 7.82 & 7.47 & 2.86 & 4.53 \\
MDP - B & 3.80 & 4.53 & 2.37 & 3.54 \\
SUD - A & 6.94 & 6.81 & 3.84 & 4.87 \\
SUD - B & 5.12 & 8.47 & 3.21 & 4.04 \\
LUN - A & 7.42 & 13.27 & 3.58 & 4.43 \\
LUN - B & 8.10 & 14.73 & 3.30 & 4.40 \\
\hline A - A horizon (Top soil) & B - B horizon (Sub soil)
\end{tabular}

Also the different methods gave different estimates for the $P$ status of the same soil. Extractable $P$ of the ten soils by $2.5 \%$ HAc (HAc - P) varied in a wide range $(3.80-101.05 \mathrm{mg} / \mathrm{kg})$. But the ranges of extractable $P$ by 0.5 $\mathrm{M} \mathrm{NaHCO}_{3}\left(\mathrm{NaHCO}_{3}-\mathrm{P}\right), \mathrm{AER}$ (AER-P) and AER + CER (AER + CER-P) were quite narrow compared to HAc-P $(4.19-22.45 \mathrm{mg} / \mathrm{kg}, 2.37-7.00$ $\mathrm{mg} / \mathrm{kg}$ and $3.54-21.31 \mathrm{mg} / \mathrm{kg}$ respectively). Although anion exchange resin shows a neutral reaction in the soil / solution / resin system, anion exchange resin in the presence of cation exchange resin extracted a greater quantity of soil $P$ than anion exchange resin alone. This tendency is very similar to previous observations by Vaidyanathan and Talibudeen (1970). The Anion exchange resin extractable $P$ values in soils of the field experiment obtained by employing $4 \mathrm{~h}$ shaking time were much lower than that of other extractants ( $2.5 \% \mathrm{HAc}_{1} 0.5 \mathrm{M} \mathrm{NaHCO}_{3}$ and AER + CER - 4h) ranging from $2.37 \mathrm{mg} / \mathrm{kg}$ to $7.00 \mathrm{mg} / \mathrm{kg}$. But the values by all four methods showed highly significant linear correlations between each other $(P<$ 0.001 ) with correlation coefficients falling in the range of $0.806<r<0.999$. The highest correlation was obtained between HAc-P and AER + CER-P ( $r$ $=0.999)$ and the lowest was between $\mathrm{HAc}-\mathrm{P}$ and $\mathrm{NaHCO}_{3}-\mathrm{P}(r=0.806)$.

The goodness of fit of soil test data and corresponding plant indices to Cate and Nelson statistical model can be used to evaluate the suitability of soil $P$ testing methods. Such a soil test can also be calibrated to get the critical soil P levels. Cate and Nelson statistical model (Cate and Nelson, 1971) provides a method for determining the dividing line, or the critical level between two categories of soils; viz., high probability of response (low soil $P$ status) and low probability of response (high soil $P$ status) to applied $P$. Each soil $P$ data set (Table 2) was arranged in the ascending order with 
corresponding RY\% values for Pueraria (Table 3), and by a simple iterative process a series of $R^{2}$ values were obtained for arbitrary divisions made into high and low $P$ status made at various levels of soil $P$.

Table 3: RY\% of Pueraria phaseoloides in each soil series

\begin{tabular}{lc}
\hline Soil series & RY\% \\
\cline { 2 - 2 } & Based on dry weight \\
\hline BOR - A & 109.01 \\
BOR - B & 67.81 \\
PAL - A & 95.43 \\
PAL - B & 94.15 \\
MDP - A & 62.82 \\
MDP - B & 74.47 \\
SUD - A & 59.45 \\
SUD - B & 46.49 \\
LUN - A & 84.66 \\
LUN - B & 82.24 \\
\hline
\end{tabular}

A-A horizon, B-B horizon

The $R^{2}$ was calculated for each arbitrary division and the division at which $R^{2}$ becomes maximum is taken as the critical level of soil $P$ for the particular soil-plant combination, with respect to the method tested. The value of $R^{2}$ is also an indication of the degree of fitness of the data set to the model. The calculated $R^{2}$ values, and the critical level for each soil $P$ test are given in Table 4.

Table 4 : Highest $R^{2}$ values and the soil critical levels obtained by Cate and Nelson statistical procedure

\begin{tabular}{lcc}
\hline Soil P test method & \multicolumn{2}{c}{$\mathrm{R}^{2}$} \\
\cline { 2 - 3 } $2.5 \%$ Acetic acid & Dry weight basis & Critical level $\mathrm{mg} / \mathrm{kg}$ \\
Olsen bicarbonate & $0.628^{\star \star}$ & 7.80 \\
AER - 4h & $0.449^{\star}$ & 8.47 \\
AER + CER - 4h & $0.460^{\star}$ & 3.84 \\
\hline \multicolumn{2}{c}{${ }^{\star \star \star} P<0.001,{ }^{* \star} P<0.01,{ }^{*} P<0.05$} & 5.34 \\
\hline
\end{tabular}

Among the different $P$ test methods used in the field experiment. $2.5 \%$ HAC $-P$ values showed the highest correlation with relative yields of Pueraria fitting significantly to the Cate and Nelson model with $R^{2}$ of $0.628(P<0.01)$ for dry weight of vegetative parts. Thus the $2.5 \%$ HAc-P values could 
account for the variation of $63 \%$ of the production of vegetative parts of Pueraria in different soil condition in the field. The correlation coefficients $R^{2}$ between AER - $P$ at $4 \mathrm{~h}$ extraction and relative yields of dry weight of Pueraria was $0.460(P<0.05)$ which explained only $46 \%$ of the variation in the production of dry weight of Pueraria. The situation was much the same with (AER + CER) - P also. Both AER - P and (AER + CER) - P showed poor correlations with relative yields of Pueraria compared to $2.5 \% \mathrm{HAC}-\mathrm{P}$. $0.5 \mathrm{M} \mathrm{NaHCO}_{3}-\mathrm{P}$ showed a poorest correlation $\left(\mathrm{R}^{2}=0.449, \mathrm{P}<0.05\right)$ with dry weight of the vegetative parts of Pueraria explaining only $45 \%$. of variation in dry matter production (Table 4). There was no clear geometrical relationship between soil $P$ values by different extraction methods and leaf $P$ concentration and $P$ uptake of Pueraria.

The results of the field experiment showed that, out of the soil $P$ test methods examined, $2.5 \%$ HAc - P gave the best correlation with plant yield under different soil conditions. The correlation was poorest with $0.5 \mathrm{M}$ $\mathrm{NaHCO}_{3}-\mathrm{P}$ values. Threshold $\mathrm{P}$ levels as determined by the correlation data were 7.8, 3.84, 5.34 and $8.47 \mathrm{mg} / \mathrm{kg}$ for HAC - P, AER - P, (AER + CER) - $\mathrm{P}$ and $\mathrm{NaHCO}_{3}-\mathrm{P}$ respectively. The $2.5 \% \mathrm{HAc}$ method is simple and much economical for soil phosphorus estimation compared to other three methods. The $2.5 \% \mathrm{HAc}$ can also be used as a multi - element extractant for the estimation of soil potassium and magnesium (Anonymous, 1985). Therefore, it is very attractive as a routine soil testing method, compared to single element estimation methods.

\section{CONCLUSION}

Results showed that $2.5 \%$ HAc-P accounted for $63 \%$ of the variation in relative dry matter weight and therefore considered the best extractant for the determination of available $P$ of soil. As other methods also accounted for only $45-46 \%$ of the variation of relative dry matter weight, they are inferior to HAC method. The threshold level for $2.5 \%$ HAC - P was found to be $7.8 \mathrm{mg} / \mathrm{kg}$ serves as an index for separating soils on the basis of $P$ fertility in respect of leguminous creeping cover crops. As $2.5 \%$ HAc method is a multi-element, rapid and economical extraction method, it is more attractive than other methods for routine work in soils of Low Country Intermediate Zone of Sri Lanka. 


\section{REFERENCES}

Anon, (1985). Advisory soil analysis and interpretations, Bulletine of Macauley Institute for Soil Research and Scottish Agricultural Colleges, Liason Group p. 4.

Cate, R.S. Jr. and Nelson, L.A. (1971). A simple statistical procedure for partitioning soil test correlation data into two classes. Soil Science Society of American Proceedings 35, 658 - 660 .

Manual of analytical methods of soils and plant Analysis. (2000). Soils and Plant Nutrition Division, Coconut Research Institute, Lunuwila, Sri Lanka.

Murphy, J. and Riley, J.P. (1962). A Modified single solution method for the determination of phosphate in natural waters. Anal. Chim. Acta. 27, 31-36.

Olsen, S.R. Cole, C.V. Watanabe, F.S. and Dean, L.A. (1954). Estimation of available phosphorus in soils by extraction with sodium bicarbonate. U. S. D. A., Washington, D. C. Circ. No. 939, p. 1-19.

Sibbesen, E. (1977). A simple ion-exchange resin procedure for extracting plant-available elements from soil. Plant and Soil, 46, 665-669.

Sibbesen, E. (1978). An investigation of the anion exchange resin method for soils phosphate extraction. Plant and Soil 50, 305-321.

Somasiri, L.L.W and Edwards, A.C. (1992). An ion exchange resin method for nutrient extraction of Agricultural Advisory soil samples. Communication in Soil Science and Plant Analasis 23 (7 \& 8), 645 657.

Vaidyanathan, L.V. and Talibudeen, O. (1970). Rate processes in the desorption of phosphorus from soils by ion-exchange resins. Journal of Soil Science 21, 173-183.

Wijebandara, D.M.D.I. and Somasiri, L.L.W. (1994). Comparison of routine laboratory methods for the estimation of plant available phosphorus in soils of the Low Country Intermediate Zone of Sri Lanka. Tropical Agricultural Research 6, 211-222. 